\title{
Ultrasound assisted in-situ separation of sophorolipids in multi-phase fermentation system to achieve efficient production
}

\author{
Yang Chen ${ }^{1}$, Ya Li ${ }^{1}$, Chang Liu ${ }^{1}$, Ying-Ping Zhuang ${ }^{1}$, Xiwei Tian ${ }^{1}$, and $\mathrm{Ju} \mathrm{Chu}^{2}$ \\ ${ }^{1}$ East China University of Science and Technology \\ ${ }^{2}$ State Key Laboratory of Bioreactor Engineering
}

November 7, 2020

\begin{abstract}
Sophorolipids (SLs) are regarded as one of the most promising biosurfactants. They have a low toxicity and are easily degradable without polluting the environment. However, high production costs are the main obstacle to extended SLs application. Semicontinuous fermentation is a promising technology for achieving high SLs productivity, which is based on in-situ separation. In this study, the sedimentation mechanism of SLs was analyzed. The formation of a hydrophobic mixture of SLs and oil was a key factor in sedimentation. The hydrophobicity and density of the mixture determined SLs sedimentation rate. According to the mechanism, ultrasonic enhanced sedimentation technology (UEST) was introduced, by which the sedimentation rates were increased by $46.9 \%$ to $485.4 \%$ with different Oil/SLs ratios. UEST-assisted real-time rational in-situ separation and semicontinuous fermentation were performed. We observed that SLs productivity and yield were $2.15 \mathrm{~g} / \mathrm{L}$ and $0.58 \mathrm{~g} / \mathrm{g}$, whereas the loss ratio of cells, glucose, and oil was reduced by $68.2 \%, 16.2 \%$, and $65.5 \%$, respectively. In-situ SLs separation efficiency and rate were increased by $34.5 \%$ and $26.4 \%$, respectively. This study provides the foundation and new horizon for the optimization of the SLs fermentation process.
\end{abstract}

\section{Graphical Abstract}




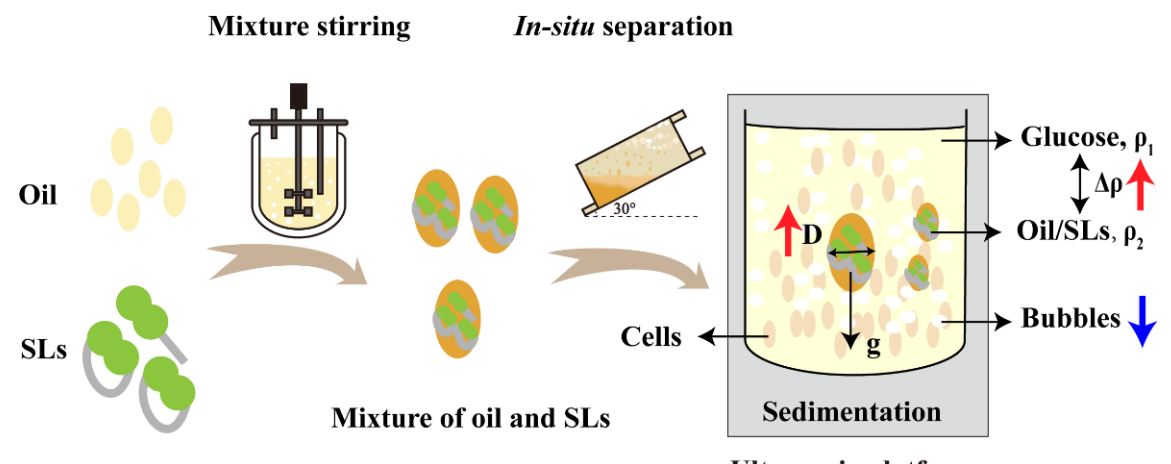

Ultrasonic platform
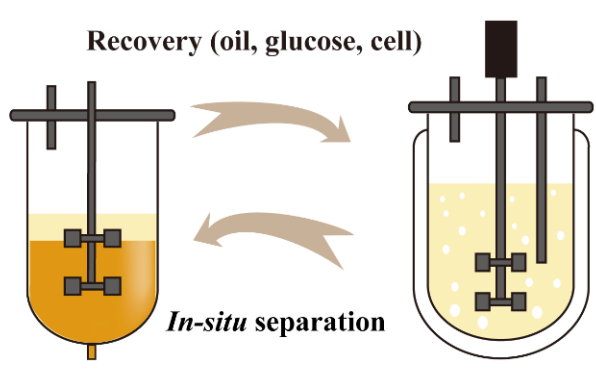

Washing tank

Fermenter

Ultrasound assisted in-situ separation of sophorolipids in multi-phase fermentation system to achieve efficient production

Running title: Efficient SLs production by ultrasound assistance

Yang Chen ${ }^{a}$, Ya Li ${ }^{\mathrm{a}}$, Chang Liu ${ }^{\mathrm{a}}$, Yingping Zhuang ${ }^{\mathrm{a}}$, Xiwei Tian ${ }^{\mathrm{a} *}, \mathrm{Ju} \mathrm{Chu}^{\mathrm{a} *}$

${ }^{a}$ State Key Laboratory of Bioreactor Engineering, East China University of Science and Technology, Shanghai 200237, China

*Author for correspondence

Address:

Ju Chu $\cdot$ Xiwei Tian

State Key Laboratory of Bioreactor Engineering, East China University of Science and Technology

P.O. box 329, 130 Meilong Road, Shanghai 200237, People's Republic of China

Tel: +86-21-64253021; Tel: +86-21-64253853

E-mail address: juchu@ecust.edu.cn (Ju Chu), tahfy@163.com (Xiwei Tian)

\section{Funding}

This work was financially supported by the National Key Research Development Program of China (No. 2019YFA0904803).

Abstract:Sophorolipids (SLs) are regarded as one of the most promising biosurfactants. They have a low toxicity and are easily degradable without polluting the environment. However, high production costs are the main obstacle to extended SLs application. Semi-continuous fermentation is a promising technology for achieving high SLs productivity, which is based on in-situ separation. In this study, the sedimentation mechanism of SLs was analyzed. The formation of a hydrophobic mixture of SLs and oil was a key factor 
in sedimentation. The hydrophobicity and density of the mixture determined SLs sedimentation rate. According to the mechanism, ultrasonic enhanced sedimentation technology (UEST) was introduced, by which the sedimentation rates were increased by $46.9 \%$ to $485.4 \%$ with different Oil/SLs ratios. UEST-assisted real-time rational in-situ separation and semi-continuous fermentation were performed. We observed that SLs productivity and yield were $2.15 \mathrm{~g} / \mathrm{L}$ and $0.58 \mathrm{~g} / \mathrm{g}$, whereas the loss ratio of cells, glucose, and oil was reduced by $68.2 \%, 16.2 \%$, and $65.5 \%$, respectively.In-situ SLs separation efficiency and rate were increased by $34.5 \%$ and $26.4 \%$, respectively. This study provides the foundation and new horizon for the optimization of the SLs fermentation process.

Keywords: Sophorolipids; Multiphase system; Ultrasonic enhanced sedimentation; Real-time; In-situ separation

\section{Introduction}

Sophorolipids (SLs), which are regarded as one of the most promising biosurfactants, have been widely used in cosmetic, food, pharmaceutical fields due to their low toxicity and high biodegradability (Jahan et al., 2020; Van Bogaert et al., 2007). Many microorganisms can synthesize SLs, including Candida (Gaur et al., 2019), Pichia(Thaniyavarn et al., 2008), andRhodotorula (Sen et al., 2017). Candida bombicola is the most widely adopted specie due to its high efficiency of SLs production (Zhou et al., 2019). SLs are the mixtures of many structural derivatives consisting of two parts, a hydrophilic sophorose and a 16-18 carbon hydrophobic hydroxyl fatty acid with general 16-18 carbon atoms (Fig. 1) (Chen et al., 2020). The differences of SLs structures are dependent on the degree of acetylation, the length of carbon chain, the unsaturation of fatty acids, and internal esterification, which further determined the properties of SLs (David et al., 2003; Hu and Ju, 2001; Jimnez-Pealver et al., 2020). Therefore, SLs fermentation process is a complex multiphase system of gas, liquid, and solid, not only containing SLs with different structural properties (solid crystallization, oily, etc.), but also possessing bubbles, lipids, glucose, cells, and other substances in the fermentation broth. This poses a great challenge to the effective regulation and optimization of the fermentation process.

Biosurfactants have the advantages of green production and environmental friendliness, compared with chemical surfactants. However, the high production cost of SLs is still the main factor that hinders their development and application (Ashby et al., 2013; Ma et al., 2020). Therefore, it is necessary to develop adequate process control strategies to improve production efficiency. To date, great progress has been made on SLs optimization in batch fermentations. However, the raise of SLs concentration during fermentation leads to an increase in viscosity, which further results in the difficulty in mixing and mass transfer, and finally causing a sharp decline in fermentation efficiency (Jia et al., 2017). Semi-continuous fermentation basing on in-situ separation of products can segregate part of SLs from the fermentation broth, thereby improving the rheological characteristics and maintaining efficient synthesis of SLs. Different types of devices have been developed to improve the efficiency of in-situ separation (Wang et al., 2019). In this regard, gravity sedimentation is the main method for in-situ separation of SLs. Zhang et al. (2018) found that the density of the fermentation broth could be adjusted by controlling the glucose concentration, so as to achieve the sedimentation of SLs. Subsequently, genetically modified soybean oil was used to achieve the sedimentation and separation of SLs. Although these studies have achieved good results, the mechanism of SLs sedimentation in a heterogeneous fermentation system has not yet been clearly elucidated, thus it is difficult to rationally control SLs sedimentation and separation.

In general, a large number of cells is lost during SLs in-situ separation process, so the efficiency of subsequent SLs synthesis will be significantly affected. Moreover, SLs have a strong affinity with oil, which also leads to the loss of oil, thereby reducing the substrate conversion rate. On the other hand, the improvement of separation efficiency also contributes to the efficient production of SLs. Ultrasonic enhanced sedimentation technology (UEST) consists of the use of particle agglomeration by acoustophoresis, which causes increased gravitational force from larger effective particle size to increase the sedimentation rate. UEST has been applied in improving microalgae production, sludge settling and dehydration efficiency (Hincapie Gomez et al., 2015; Maddikeri et al. 2015). Otherwise, Palme et al. (2010) reported that UEST was introduced in SLs fermentation for in-situ separation of cells, and the cell recovery was up to $99.0 \%$ without affecting the 
cell activity. However, it should be noted that only $10 \%$ of SLs could be recovered by this strategy.

In this study, the influences of oil concentrations on SLs morphology and sedimentation were investigated, and then the mechanism of SLs sedimentation was further analyzed. On this basis, UEST was introduced for in-situ separation of SLs, and finally a rational semi-continuous fermentation process was developed for highly efficient SLs production.

\section{Material and methods}

2.1. Microorganism, media, and culture conditions

C. bombicola ATCC 22214 was obtained from the Guangdong Culture Collection Center (China) and stored at -80 in $20 \%$ glycerol solution. The seed medium consisted of $50 \mathrm{~g} / \mathrm{L}$ glucose, $1 \mathrm{~g} / \mathrm{L} \mathrm{KH}_{2} \mathrm{PO}_{4}, 4 \mathrm{~g} / \mathrm{L}$ $\left(\mathrm{NH}_{4}\right)_{2} \mathrm{SO}_{4}, 0.5 \mathrm{~g} / \mathrm{L} \mathrm{MgSO}_{4} * 7 \mathrm{H}_{2} \mathrm{O}$, and $10 \mathrm{~g} / \mathrm{L}$ corn steep liquor $(\mathrm{CSL})$. The seed was cultured in a $1 \mathrm{~L}$ baffled shake flask with $200 \mathrm{~mL}$ working volume at $200 \mathrm{rpm}$ and 25 for $48 \mathrm{~h}$.

The initial fermentation medium in a $5 \mathrm{~L}$ bioreactor (Shanghai Guoqiang Bioengineering Equipment Co., Ltd., China) consisted of glucose $100 \mathrm{~g} / \mathrm{L}, \mathrm{KH}_{2} \mathrm{PO}_{4} 1 \mathrm{~g} / \mathrm{L},\left(\mathrm{NH}_{4}\right)_{2} \mathrm{SO}_{4} 4 \mathrm{~g} / \mathrm{L}, \mathrm{MgSO}_{4} * 7 \mathrm{H}_{2} \mathrm{O} 0.5 \mathrm{~g} / \mathrm{L}, \mathrm{CSL} 10$ $\mathrm{g} / \mathrm{L}$. All culture media were sterilized at 115 for $30 \mathrm{~min}$. The initial volume of $2.5 \mathrm{~L}$ with an inoculum of $3 \%$ was cultured at 25 for $168 \mathrm{~h}$. Aeration at $0.5 \mathrm{vvm}$ and dissolved oxygen (DO) above $30 \%$ of the saturation concentration were maintained by adjusting the agitation in a stepwise manner. A pH of 3.5 was maintained by addition of $4 \mathrm{M} \mathrm{NaOH}$ solution, during the whole process. The fed-batch fermentation cycle was $168 \mathrm{~h}$. During fermentation, glucose concentration in the broth was maintained at 30-80 g/L. Oil supplementation rate was $0.5 \mathrm{~g} / \mathrm{L} / \mathrm{h}$ for the first $24 \mathrm{~h}$, after which oil concentration was maintained at $2-15 \mathrm{~g} / \mathrm{L}$, according to oil consumption. The semi-continuous fermentation period was $378 \mathrm{~h}$, and SLs was intermittently separated by the separation unit every $72 \mathrm{~h}$. The supplementation rate of glucose and rapeseed oil was optimized according to the sedimentation rate of SLs. After every two in-situseparations, $1 / 5$ of the initial nutrition was supplemented.

\subsection{SLs sedimentation mechanism}

\subsubsection{Influences of oil to SLs ratios on SLs morphology and sedimentation}

The ratio of oil to SLs $(\mathrm{O} / \mathrm{S})(0.075,0.10,0.13,0.15,0.18,0.20,0.22,0.23,0.25,0.30 \mathrm{~g} / \mathrm{g})$ was quickly detected and regulated by the low-field nuclear magnetic method (Chen et al., 2019). SLs morphology was observed by optical microscopy (BMDH200 microscope, Sunny Optical Technology Co., Ltd), and the main structures of SLs with different morphologies were analyzed by LC-MS (Chen et al., 2020).

Furthermore, $10 \mathrm{~mL}$ of the fermentation broth with different $\mathrm{O} / \mathrm{S}$ ratios were processed by standing still to observe the SLs sedimentation, and the volume of lower layer was recorded at different time points until it was unchanged during 2 hours.

\subsubsection{Measurements of broth viscosity and SLs particle size}

Twenty milliliters of broth with different $\mathrm{O} / \mathrm{S}$ ratios were obtained to measure the viscosity of supernatant with a viscosity meter (Brookfield DV-II). Another $5 \mathrm{~mL}$ broth was thoroughly mixed, and the SLs particle size was analyzed by nanometer size and ZETA potential analyzer (Beckman Coulter Nano-ZS).

\subsection{Effect of ultrasound assistance on SLs precipitation}

\subsubsection{Effect of ultrasonic ultrasound assistance on cell activity and SLs production}

An appropriate amount of fermentation broth was obtained and treated at different ultrasonic times $(0$, 10, 20, 30, 40, 50, and $60 \mathrm{~min})$ and power $(100,200$, and $300 \mathrm{~W})$ in a $10 \mathrm{~L}$ ultrasonic cleaning machine (SHT-70al, $40 \mathrm{kHz})$. And then, the treated broth was diluted at appropriate times and coated on the plate to observe the cell activity. Otherwise, the strains after different ultrasonic treatments were concentrated by centrifugation, resuspended, and inoculated into a medium contained only glucose and oil ( $50 \mathrm{~mL}$ of 
fermentation broth strains were inoculated into a $500 \mathrm{~mL}$ shake flask with $50 \mathrm{~mL}$ working volume). And compared strain growth and SLs production.

\subsection{Semi-continuous fermentation based on ultrasonic assisted treatment}

In semi-continuous fermentation, the optimal $\mathrm{O} / \mathrm{S}$ was adopted to rational control the sedimentation of SLs for in-situ separation. According to our previously developed SLs separation equipment (Liu et al., 2019), the improved in situ separation platform was shown in Fig 2. The fermentation broth was rapidly pumped into the separation unit, which was placed in the ultrasonic machine, by a peristaltic pump at $5 \mathrm{~mL} / \mathrm{s}$. The ultrasonic power and time were controlled at $100 \mathrm{~W}$ and $10 \mathrm{~min}$. Subsequently, the SLs was intermittently discharged from port $\mathrm{c}$ for $1 \mathrm{~min}$, and the supernatant was refilled from port $\mathrm{b}$ to the fermenter until the SLs concentration in the fermenter was lower than $60 \mathrm{~g} / \mathrm{L}$. Finally, the separated crude SLs was washed by $1 / 2$ proportion of sterile water (v/v), and thoroughly mixed by stirring. After standing for 20 min, the supernatant was pumped back to the fermenter to recover the biomass, glucose and oil. Due to the loss of biomass after the operation of SLsin-situ separation, medium and sterile water were replenished to the initial volume of $2.5 \mathrm{~L}$.

\subsection{Analytical methods}

Glucose concentration was analyzed by an enzymatic bio-analyzer (SBA-40C, Shandong Academy of Sciences, China). Oil concentration in the broth was quickly determined by the low-field nuclear magnetic method (Chen et al., 2019). For oil content determination, three parallel broth samples were extracted twice, using the same volume of n-hexane. The upper layer was transferred to another tube and dried in an oven for $24 \mathrm{~h}$, until constant weight. The bottom layer was washed twice with alcohol and dried at 80 for $24 \mathrm{~h}$ to measure dry cell weight (DCW). The concentrations and structures of SLs were determined by HPLC and HPLC-MS, respectively (Chen et al., 2020).

\subsection{Data analysis}

As the fermentation went on, SLs was gradually accumulated in the broth and once the $\mathrm{O} / \mathrm{S}$ reached at a certain range, the SLs sedimentation was occurred. The average sedimentation rate was calculated by formula (1). By fitting the height of SLs sedimentation was directly proportional to the concentration of SLs, formula (2) was obtained (Fig. 4A). The sedimentation rate formula related to SLs concentration could be derived in (3).

$$
\begin{aligned}
& V=\frac{H_{1}-H_{2}}{2 t}(1) \\
& \frac{H_{2}}{H_{1}}=0.0031 \times c-0.0001(2) \\
& V=\frac{H_{1}-H_{1}(0.0031 \times c-0.0001)}{2 t}(3)
\end{aligned}
$$

Where $V$ is the average sedimentation rate of SLs in $\mathrm{cm} / \mathrm{s}, \mathrm{H}_{1}$ is the height of broth in the $10 \mathrm{~mL}$ sedimentation tube in $\mathrm{cm}, \mathrm{H}_{2}$ is the height of SLs settled in the $10 \mathrm{~mL}$ sedimentation tube in $\mathrm{cm}, \mathrm{t}$ is settling time in $\mathrm{s}, \mathrm{c}$ is SLs concentration in $\mathrm{g} / \mathrm{L}$.

In this study, the sedimentation mechanism and ultrasound assisted efficiency were analyzed by the Stokes law as shown in (4) (Yang et al., 2015).

$V=\frac{2 r^{2}\left(\rho_{2}-\rho_{1}\right) g}{9 \mu}(4)$

Where $\mathrm{V}$ is the sedimentation rate of SLs particles under ideal condition in $\mathrm{m} / \mathrm{s}, \mathrm{r}$ is the radius of SLs particles in $\mathrm{m}, \rho_{1}$ is the density of broth in $\mathrm{kg} / \mathrm{m}^{3}, \rho_{2}$ is the density of SLs particles in $\mathrm{kg} / \mathrm{m}^{3}, \mathrm{~g}$ is the gravitational acceleration in $\mathrm{m} / \mathrm{s}^{2}, \mu$ is the viscosity of broth in $\mathrm{Pa}^{*} \mathrm{~s}$.

Due to the consideration of working volume change by feeding, all the presented data in Figures and Tables were normalized to the initial volume. All experiments were performed in triplicate. 


\section{Results and Discussion}

\subsection{Effects of $\mathrm{O} / \mathrm{S}$ ratios on SLs morphology and sedimentation}

Under different $\mathrm{O} / \mathrm{S}$ ratio conditions, SLs would exhibit different morphologies. When the $\mathrm{O} / \mathrm{S}$ value was higher than $0.04 \mathrm{~g} / \mathrm{g}$, the SLs presented oily characteristics. The microscopic results showed that biomass and broth were enclosed by the mixture of oil and SLs due to their strong hydrophobicity. Under the action of gravity, SLs began to gradually precipitate, and the fermentation broth showed obvious stratification (Fig. 3). With the decrease of $\mathrm{O} / \mathrm{S}$ ratio, the fermentation broth began to be in an emulsified state, and SLs no longer stratified with fermentation broth, thus presenting a relatively uniform state (Fig. 3). With the further decrease of $\mathrm{O} / \mathrm{S}$ ratio $(<0.02 \mathrm{~g} / \mathrm{g})$, crystalline SLs gradually appeared in the broth (Fig. 3). By comparing the structure compositions of SLs in different forms, it could be found that under high $\mathrm{O} / \mathrm{S}$ ratio condition $(>0.04 \mathrm{~g} / \mathrm{g})$, the number of deposited SLs, which was mainly a mixture of lactone- and acidic-forms SLs, accounted for $92 \%$ of the total SLs, while the supernatant only contained a portion of lactone- and acidic- form SLs. In contrast, when the O/S ratio was low $(<0.02 \mathrm{~g} / \mathrm{g})$, the crystalline SLs composed of lactone-form SLs accounted for $38 \%$ of the total SLs, whereas the broth consisted of lactoneand acidic-form SLs (Table S1). These results were in agreed with the conclusion that acidic-form SLs has stronger hydrophilicity and lactone-form SLs has stronger hydrophobicity. Notably, the crystalline SLs could not settle on its own, but as the $\mathrm{O} / \mathrm{S}$ ratio increased, it could be found through the microscope that the crystalline SLs would be surrounded by oily particles to form oily SLs, and then began to precipitate (Fig. S1). Therefore, it was further inferred that the settleability of SLs was dependent on their morphologies, which could be contributed to the hydrophobicity of lactone-form SLs as well as the oil and SLs contents.

\subsection{The mechanism of SLs sedimentation}

When the $\mathrm{O} / \mathrm{S}$ ratio was greater than $0.04 \mathrm{~g} / \mathrm{g}$, the sedimentation height was directly proportional to the concentration of SLs (Fig. 4A), and then the average sedimentation rate could be obtained by formula (1)-(3). According to formula (3), although the average sedimentation rate was related to SLs concentration in the broth, the oil content would significantly affect the settling time, thus exhibiting that $\mathrm{O} / \mathrm{S}$ ratio was correlated to the average sedimentation rate (Fig. 4B). With the increase of $\mathrm{O} / \mathrm{S}$ ratio, the average of sedimentation rate of SLs was significantly enhanced, which reached the maximum value of $0.075 \mathrm{~cm} / \mathrm{s}$ at $0.25 \mathrm{~g} / \mathrm{g}$. However, it started to decrease with the further increase of $\mathrm{O} / \mathrm{S}$ ratio.

Stokes formula is used to calculate the sedimentation rate of spherical particles under an ideal condition. Although the SLs sedimentation is a complicated process and it is impossible to achieve an ideal environmental state, the Stokes formula can still give important theoretical guidance. According to formula 4, the sedimentation rate of spherical particles was mainly determined by the radius, density, and viscosity. Analysis of SLs particle size showed that when SLs was oily, the radius of SLs particle increased with the $\mathrm{O} / \mathrm{S}$ ratio and the maximum radius maintained at $1.5 \mathrm{~mm}$ once the $\mathrm{O} / \mathrm{S}$ ratio exceeded $0.04 \mathrm{~g} / \mathrm{g}$ (Fig. 5A). In the real fermentation process, the $\mathrm{O} / \mathrm{S}$ ratio was usually above $0.04 \mathrm{~g} / \mathrm{g}$, therefore the particle size of SLs seemed to be less influence on the SLs settling. In addition, the viscosity of fermentation broth was an important factor affecting the sedimentation rate of SLs. In the early stage of fermentation, the viscosity of supernatant had marginal changes. When the SLs concentration was higher than $250 \mathrm{~g} / \mathrm{L}$, the supernatant viscosity was sharply increased (Fig. 5B). The high viscosity would affect the mixing and mass transfer, and reduce the production efficiency of SLs in the late fermentation. Therefore, when SLs concentration was around 200-220 g/L, the in-situ separation would be carried out in this study, thus viscosity had limited influence on SLs precipitation. By the density analysis, it was shown that after mixing SLs and oil, the density decreased with the increase of $\mathrm{O} / \mathrm{S}$ ratio (Fig. 5C). However, $1.0 \mathrm{~g}$ SLs was found to be bound to a maximum of $0.3 \mathrm{~g}$ oil (Fig. S2). Therefore, the minimum density of the mixture of SLs and oil was $1.10 \mathrm{~g} / \mathrm{cm}^{3}$. In contrast, the density of the supernatant was mainly determined by glucose concentration, which was less than $100 \mathrm{~g} / \mathrm{L}$ in real fermentation process, so the density of the supernatant was much lower than the mixture of SLs and oil (Fig. 5D), and density difference was the main reason determining the SLs settling or floating. As the main reason for suspending SLs was the increase of oil concentration or bubbles, the density of the mixture of SLs and oil was lower than the supernatant to achieve temporary suspension, 
but SLs would be re-sedimented by standing still.

As mentioned above, the SLs sedimentation requires the formation of a mixture of SLs and oil. When the $\mathrm{O} / \mathrm{S}$ ratio was low $(<0.04 \mathrm{~g} / \mathrm{g})$, crystallized or emulsified SLs would not settle by itself. When the $\mathrm{O} / \mathrm{S}$ ratio was high $(>0.04 \mathrm{~g} / \mathrm{g})$, an oily mixture was formed and began to settle. With the increased of $\mathrm{O} / \mathrm{S}$ ratio, the hydrophobicity of the mixture was strengthened, thus the settling rate was accelerated under gravity action.

In the settling process, the hydrophobic mixture formed by SLs and oil was the key to settling (Fig. 6). The stronger hydrophobicity, the faster sedimentation rate will be. In terms of sedimentation rate, it was mainly dependent on the density difference of supernatant and the mixture. To improve the efficiency of SLs separation and reduce the loss of substances during in-situ separation process, low glucose concentration and appropriate $\mathrm{O} / \mathrm{S}$ ratio should be adopted.

\subsection{Enhancement of sedimentation efficiency by UEST}

Although SLs sedimentation could be achieved by adjusting the $\mathrm{O} / \mathrm{S}$ ratio in the broth, it was common to result in some losses of biomass, glucose, and oil during the in-situ separation process. Especially for oil, its loss and SLs sedimentation efficiency always presented a contradiction, and it would be lost a lot at high O/S ratio of $0.25 \mathrm{~g} / \mathrm{g}$, even if SLs could be quickly settled. On the other hand, under the low $\mathrm{O} / \mathrm{S}$ ratio condition, the oil loss was reduced, but corresponding SLs sedimentation rate also slowed down. Therefore, UEST was introduced to accelerate the sedimentation rate of SLs and simultaneously reduce the loss of substrate and biomass. Ultrasound not only accelerates the aggregation of SLs particles, enhancing the gravity force, but also rapidly removes air bubbles, reducing the interference of air bubbles on SLs precipitation (Fig. S3A). Moreover, it could be found that after the treatment of ultrasound, the cell viability and SLs production capability would not be affected, demonstrating that it was feasible to introduce UEST to improve the efficiency of SLs sedimentation. (Fig. S3 B and C).

The average sedimentation rate of SLs enhanced with the increase of the ultrasonic time and power (Fig. 7A, $\mathrm{B}$ and $\mathrm{C}$ ). The maximum sedimentation rate increase by $46.9 \%$ to $485.4 \%$ with UEST from high to low $\mathrm{O} / \mathrm{S}$ ratios (Fig. $7 \mathrm{D}$ ). When the $\mathrm{O} / \mathrm{S}$ was $0.10 \mathrm{~g} / \mathrm{g}$, the sedimentation rate reached $0.0165 \mathrm{~cm} / \mathrm{s}$, independent on ultrasonic power. Since low O/S ratio leaded to less loss in in-situ separation process, UEST could not only reduces the influence of oil on viscosity, but also further reduces the loss of oil and accelerates SLs separation under low $\mathrm{O} / \mathrm{S}$ ratio condition. In the following experiments, the ultrasonic power of $100 \mathrm{~W}$ and the time of $10 \mathrm{~min}$ (the height of separation device was $10 \mathrm{~cm}$ and the sedimentation rate was $0.0165 \mathrm{~cm} / \mathrm{s}$ ) were adopted to achieve effective sedimentation.

\subsection{Semi-continuous fermentation of SLs production by in-situ separation strategy with UEST}

The SLs sedimentation was regulated by the S/O ratio, and the sedimentation efficiency was related to supernatant density dependent on glucose concentration. Therefore, before in-situ separation of SLs, the $\mathrm{O} / \mathrm{S}$ ratio was adjusted to $0.10-0.12 \mathrm{~g} / \mathrm{g}$, and the glucose concentration was controlled at approximately 30 $\mathrm{g} / \mathrm{L}$. The whole semi-continuous fermentation cycle lasted $378 \mathrm{~h}$, during which 4 times of $\mathrm{in}$-situ separation of SLs were conducted with UEST once the SLs concentration in the broth reached 200-220 g/L, and the total of $2039.9 \mathrm{~g}$ SLs was produced with the consumption of $1545.7 \mathrm{~g}$ oil and $1979.3 \mathrm{~g}$ glucose respectively (Fig. 8A and B). Through the analysis of SLs productivity and yield during different phases, it was found that the cell activity has been maintained at a high level throughout the whole fermentation process and the average SLs productivity and yield reached $2.15 \mathrm{~g} / \mathrm{L}$ and $0.58 \mathrm{~g} / \mathrm{g}$ respectively (Fig. 8C). Moreover, UEST in-situ separation could reduce the losses of biomass, glucose and oil by $68.2 \%, 16.2 \%$, and $65.5 \%$, respectively (Table 1), in comparison to direct in-situ separation without UEST, thus achieving efficient SLs separation under low O/S ratio condition. Correspondingly, thein-situseparation efficiency and SLs separation rate improved by $34.5 \% \%$ and $26.4 \%$, respectively (Table 1 ).

SLs has been regarded as a green and sustainable biosurfactants, but their high production costs limit large-scale application and development (Jimenez-Penalver et al., 2019). Coupling fermentation on the basis of in-situ product separation is one of the most effective ways to reduce production costs and improve 
productivity (Table 2). Wang et al. (2020) designed a simple in-situ separation device coupled with the bioreactor and adopted high cell density fermentation to achieve high-efficient production of SLs. After running for $480 \mathrm{~h}$, the productivity and yield of SLs were $2.39 \mathrm{~g} / \mathrm{L} / \mathrm{h}$ and $0.73 \mathrm{~g} / \mathrm{g}$, respectively, with an average separation efficiency of $74.3 \%$. Zhang et al. (2018) developed a new bioreactor with dual ventilation pipes containing dual sieve plates (DVDSB) for semi-continuous fermentation of SLs. By regulating the air pressure and different sources of oil (transgenic or non-transgenic oil), the gravity sedimentation of SLs at the bottom of bioreactor could be accomplished with SLs titer, productivity, and yield of $477 \mathrm{~g} / \mathrm{L}, 1.59$ $\mathrm{g} / \mathrm{L} / \mathrm{h}$ and $0.60 \mathrm{~g} / \mathrm{g}$, respectively. Otherwise, Dolman et al. (2017) suggested that the glucose concentration could adjust the density of fermentation broth thereby controlling the ups and downs of SLs. The whole fermentation process lasted $1023 \mathrm{~h}$ to produce $623 \mathrm{~g} / \mathrm{L}$ SLs, and during the SLs in-situseparation process, the recovery rate of SLs was as high as $86.0 \%$, which was 9 times concentration of previously reported. Apart from SLs separation by gravity sedimentation, Liu et al. (2019) realized the SLs separation in the upper layer of the broth through the principle of froth flotation. Subsequently, part of biomass and glucose could be recovered by washing the settled SLs, and the final titer and productivity of SLs were $342 \mathrm{~g} / \mathrm{L}$ and $1.55 \mathrm{~g} / \mathrm{L} / \mathrm{h}$, respectively. Though these strategies have achieved relatively satisfactory results in the in-situ separation of SLs, the mechanism of SLs separation either by gravity sedimentation or by froth flotation was still not been clearly elucidated, which led to a blind separation process and low separation efficiency. Oil or glucose concentration has been pointed out to possess a significant impact on the settlement of SLs (Zhang et al., 2018), however, these researches focused more on the final results and failed to further analyze the causes of the sedimentation, resulting in big differences in different studies. Herein, the sedimentation mechanism of SLs was studied and it was found that the O/S ratio was the key factor affecting the SLs morphology and subsequent settling. In contrast, the sedimentation rate was dependent on the hydrophobicity of the oily SLs as well as the density difference with the broth. These results provided a solid foundation for rational regulation of SLs deposition. On the other hand, the UEST can accelerate the particle collision, make the particle become larger, eliminate the air bubbles, and further reduces the settling resistance (Luo et al., 2019). Palme et al. (2010) and Hincapie Gomez et al. (2015) applied ultrasonic enhanced deposition technology in the separation and recovery of microalgae and yeast cells, respectively. In this work, UEST was introduced to enhance the sedimentation of SLs, simultaneously greatly reduce the losses of oil, glucose, and biomass duringin-situ separation process. Moreover, semi-continuous fermentation by in-situ separation of SLs with UEST was conducted. Compared to the batch fermentation $(168 \mathrm{~h})$, the fermentation cycle was more than 2-fold longer $(378 \mathrm{~h})$, and the average productivity and yield from semi-continuous fermentation were increased by $26.5 \%$ and $23.4 \%$ respectively. This could be contributed to that the semi-continuous fermentation could separate out SLs and toxic substances in time, and allow the cells being in the optimal production environment, which also proved the feasibility of semi-continuous fermentation as a model for the efficient production of SLs. In comparison with other semi-continuous fermentations of SLs, both the productivity and yield in this work were at high levels, especially for the index of $\mathrm{Y}_{\mathrm{SLs} / \mathrm{DCW}}$ representing the SLs production yield to the DCW, its value reached $36.1 \mathrm{~g} / \mathrm{g}_{\mathrm{DCW}}$, which was $86.1 \%$ higher than the highest value in the literatures. Furthermore, the specific SLs productivity $\left(\mathrm{Q}_{\mathrm{P} / \mathrm{DCW}}\right)$ also exhibited a $41.2 \%$ higher than the highest value ever reported. It could be expected to achieve a more ideal production efficiency in combination with high cell density strategy, laying a foundation for further industrial application.

\section{Conclusion}

In this study, the mechanism of SLs sedimentation in multiphase fermentation process was elucidated for the first time. And then UEST was introduced to strengthen the SLs sedimentation rate. The real-time rational in-situ separation of SLs and semi-continuous fermentation with UEST was accomplished to achieve productivity and yield of $2.15 \mathrm{~g} / \mathrm{L}$ and $0.58 \mathrm{~g} / \mathrm{g}$ respectively as well as reduce the losses of cells, glucose, and oil by $68.2 \%, 16.2 \%$, and $65.5 \%$, respectively. The rational in-situ separation and UEST for complex multiphase systems could be extended to other biosurfactant fermentation systems to improve production efficiency.

\section{Author Contribution Statement}


Chen Y: Conceptualization, Methodology, Validation, Formal analysis, Investigation, Writing - original draft \& editing, Visualization.

Li Y, Liu C: Conceptualization, Methodology.

Chu J, Zhuang YP, Tian XW: Conceptualization, Methodology, Validation, Writing - review \& editing, Supervision, Funding acquisition.

\section{Competing interests}

The authors declare that they have no competing interests.

\section{Ethical approval}

This article does not contain any studies with human participants or animals performed by any of the authors.

\section{Acknowledgement and Funding}

This work was financially supported by the National Key Research Development Program of China (No. 2019YFA0904803). The authors thank Research Center of Analysis and Test of East China University of Science and Technology for the help on the characterization.

\section{Reference}

Ashby, R. D., McAloon, A. J., Solaiman, D. K. Y., Yee, W. C., \& Reed, M. (2013). A process model for approximating the production costs of the fermentative synthesis of sophorolipids. Journal of Surfactants and Detergents , 16, 683-691.

Chen, Y., Lin, Y. M., Tian, X. W., Li, Q. H., \& Chu, J. (2019). Real-time dynamic analysis with low-field nuclear magnetic resonance of residual oil and sophorolipids concentrations in the fermentation process of Starmerella bombicola. Journal of Microbiological Methods , 157, 9-15. https://doi.org/10.1016/j.mimet.2018.12.007.

Chen, Y., Tian, X.W., Li, Q. H., Li, Y., Chu, J., Hang, H. F., \& Zhuang, Y. P. (2020). Target-site directed rational high-throughput screening system for high sophorolipids production by Candida bombicola . Bioresource Technology, 315, 123586. https://doi.org/10.1016/j.biortech.2020.123856.

David, A. C., \& David, G. C. (2003). The effect of medium composition on the structure and physical state of sophorolipids produced by Candida bombicola ATCC 22214. 103, 31-41. https://doi.org/10.1016/S01681656(03)00067-1.

Dolman, B. M., Kaisermann, C., Martin, P. J., \& Winterburn, J. B. (2017). Integrated sophorolipid production and gravity separation.Process Biochemistry , 54, 162-171. https://doi.org/10.1016/j.procbio.2016.12.021.

Gaur, V. K., Regar, R. K., Dhiman, N., Gautam, K., Srivastava, J. K., Patnaik, S., Kamthan, M., \& Manickam, N. (2019). Biosynthesis and characterization of sophorolipid biosurfactant by Candida spp.: Application as food emulsifier and antibacterial agent.Bioresource Technology , 285, 121314. https://doi.org/10.1016/j.biortech.2019.121314.

Hincapie Gomez, E., \& Marchese, A. J. (2015). An Ultrasonically Enhanced Inclined Settler for Microalgae Harvesting. Biotechnology Progress , 31, 414-423. https://doi.org/10.1002/btpr.2031.

Hu, Y. M., \& Ju, L. K. (2001). Sophorlipid production from different lipid precursors observed with LC-MS. Enzyme and Microbial Technology , 29, 593-601. https://doi.org/10.1016/S0141-0229(01)00439-2.

Jahan, R., Bodratti, A. M., Tsianou, M., \& Alexandridis, P. (2020). Biosurfactants, natural alternatives to synthetic surfactants: Physicochemical properties and applications.Advances in Colloid and Interface Science, 275. https://doi.org/10.1016/j.cis.2019.102061. 
Jia, X. Q., Qi, L., Zhang, Y. G., Yang, X., Wang, H. G., Zhao, F. L., \& Lu, W. Y. (2017). Computational fluid dynamics simulation of a novel bioreactor for sophorolipid production. Chinese Journal of Chemical Engineering , 25, 732-740. https://doi.org/10.1016/j.cjche.2016.09.014.

Jimnez-Pealver, P., Koh, A., Gross, R., Gea, T., \& Font, X. (2020). Biosurfactants from Waste: Structures and Interfacial Properties of Sophorolipids Produced from a Residual Oil Cake. Journal of Surfactants and Detergents , 23, 481-486.

Jimenez-Penalver, P., Rodriguez, A., Daverey, A., Font, X., \& Gea, T. (2019). Use of wastes for sophorolipids production as a transition to circular economy: state of the art and perspectives. Reviews in Environmental Science and Biotechnology , 18, 413-435.

Liu, Z. P., Tian, X. W., Chen, Y., Lin, Y. M., Mohsin, A., \& Chu, J. (2019). Efficient sophorolipids production via a novel in situ separation technology by Starmerella bombicola .Process Biochemistry , 81, 1-10. https://doi:10.1016/j.procbio.2018.12.005.

Lodens, S., Roelants, S. L. K. W., Ciesielska, K., Geys, R., Derynck, E., Maes, K., Pattyn, F., Van Renterghem, L., Mottet, L., Dierickx, S., Vanhaecke, L., Devreese, B., De Maeaeneire, S. L., \& Soetaert, W. (2020). Unraveling and resolving inefficient glucolipid biosurfactants production through quantitative multiomics analyses of Starmerella bombicola strains.Biotechnology and Bioengineering , 117, 453-465. https://doi.org/10.1002/bit.27191.

Luo, X. M., Gong, H. Y., Cao, J. H., Yin, H. R., Yan, Y. P., \& He, L. M. (2019). Enhanced separation of water-in-oil emulsions using ultrasonic standing waves. Chemical Engineering Science, 203, 285-292. https://doi.org/10.1016/j.ces.2019.04.002.

Ma, X. J., Meng, L., Zhang, H. M., Zhou, L. Y., Yue, J. Y., Zhu, H. X., \& Yao, R. S. (2020). Sophorolipid biosynthesis and production from diverse hydrophilic and hydrophobic carbon substrates. Applied Microbiology and Biotechnology, 104, 77-100.

Maddikeri, G. L, Gogate, P. R., \& Pandit, A. B. (2015). Improved synthesis of sophorolipids from waste cooking oil using fed batch approach in the presence of ultrasound.Chemical Engineering Journal , 263, 479-487. https://doi.org/10.1016/j.cej.2014.11.010.

Palme, O., Comanescu, G., Stoineva, I., Radel, S., Benes, E., Develter, D., Wray, V., \& Lang, S. (2010). Sophorolipids from Candida bombicola : Cell separation by ultrasonic particle manipulation.European Journal of Lipid Science and Technology, 112, 663-673. https://doi.org/10.1002/ejlt.200900163.

Sen, S., Borah, S.N., Bora, A., \& Deka, S. (2017). Production, characterization, and antifungal activity of a biosurfactant produced byRhodotorula babjevae YS3. Microbial Cell Factories , 16, 95-108. https://doi.org/10.1186/s12934-017-0711-z.

Thaniyavarn, J., Chianguthai, T., Sangvanich, P., Roongsawang, N., \& Washio, K. (2008). Production of sophorolipid biosurfactant by Pichia anomala . Bioscience, biotechnology, and biochemistry, 72, 2061-2068.

Van Bogaert, I. N.A., Saerens, K., De Muynck, C., Develter, D., Soetaert, W., \& Vandamme, E. J. (2007). Microbial production and application of sophorolipids. Applied microbiology and biotechnology , 76, 23-34.

Van Renterghem, L., Roelants, S. L. K. W., Baccile, N., Uyttersprot, K., Claire Taelman, M., Everaert, B., Mincke, S., Ledegen, S., Debrouwer, S., Scholtens, K., Stevens, C., \& Soetaert, W. (2018). From Lab to Market: An Integrated Bioprocess Design Approach for New-To-Nature Biosurfactants Produced by Starmerella Bombicola .Biotechnology and Bioengineering , 115, 1195-1206. https://doi.org/10.1002/bit.26539.

Wang, H. M., Kaur, G., To, M. H., Roelants, S. L. K. W., Patria, R. D., Soetaert, W., \& Li, C. S. K. (2020). Efficient in-situ separation design for long-term sophorolipids fermentation with high productivity. Journal of Cleaner Production , 246, 118995. https://doi:10.1016/j.jclepro.2019.118995. 
Wang, H. M., Roelants, S. L. K. W., To, M. H., Patria, R. D., Kaur, G. S., Lau, C. Y., Van Bogaert, I. N.A., Soetaert, W., \& Li, C. S. K. (2019). Starmerella bombicola : recent advances on sophorolipid production and prospects of waste stream utilization. Journal of Chemical Technology and Biotechnology, 94, 999-1007. https://doi.org/10.1002/jctb.5847.

Yang, H. L., Fan, M. Q., Liu, A. R., \& Dong, L. P. (2015). General formulas for drag coefficient and settling velocity of sphere based on theoretical law. International Journal of Mining Science and Technology , 25, 219-223. https://doi.org/10.1016/j.ijmst.2015.02.009.

Zhang, Y. G., Jia, D., Sun, W. Q., Yang, X., Zhang, C. B., Zhao, F. L., \& Lu, W. Y. (2018). Semicontinuous sophorolipid fermentation using a novel bioreactor with dual ventilation pipes and dual sieve-plates coupled with a novel separation system. Microbial Biotechnology , 11, 455-464. https://doi.org/10.1111/17517915.13028.

Zhou, G., Tian, X. W., Lin, Y. M., Zhang, S. L., \& Chu, J. (2019). Rational high-throughput system for screening of high sophorolipids-producing strains of Candida bombicola .Bioprocess and Biosystems Engineering , 42, 575-582.

Table 1 In-situseparation parameter

\begin{tabular}{llllll}
\hline & Biomass loss rate $(\%)^{\mathrm{a}}$ & ${\text { Glucose loss rate }(\%)^{\mathrm{a}}}$ & ${\text { Oil loss rate }(\%)^{\mathrm{a}}}$ & ${\text { SLs separation rate }(\%)^{\mathrm{b}}}$ & $I n-s i$ \\
\hline UEST & $0.14 \pm 0.024$ & $5.70 \pm 0.15$ & $3.90 \pm 0.31$ & 71.4 & 7.52 \\
In-situ separation & $0.44 \pm 0.010$ & $6.80 \pm 0.02$ & $11.30 \pm 0.33$ & 56.5 & 5.59 \\
\hline
\end{tabular}

aBiomass (Glucose, oil) los rate $=\frac{c_{b}-c_{a}}{S_{\mathrm{SLs}}}$

Where $c_{b}$ is the quality before separation in $\mathrm{g}, c_{a}$ is the quality after separation in $\mathrm{g}, S_{\mathrm{SLs}}$ is the isolated SLs in $\mathrm{g}$.

bSLs separation rate $=\frac{S_{\mathrm{SLs}}}{c_{\mathrm{SLs}}}$

Where $S_{\text {SLs }}$ is the isolated SLs in g, $c_{\text {SLs }}$ is the quality of SLs before separation in $g$.

$\mathrm{cIn}-$ situ separation efficiency $=\frac{S_{\mathrm{SLs}}}{t}$

Where $S_{\text {SLs }}$ is the isolated SLs in $g, t$ is separation of time in min.

Table 2 Comparison between fed-batch fermentation and semi-continuous fermentation

\begin{tabular}{llllll}
\hline Strain & substrate & Fermentation period $(\mathrm{h})$ & Productivity $(\mathrm{g} / \mathrm{L} / \mathrm{h})$ & Yield $(\mathrm{g} / \mathrm{g})$ & $\mathrm{Q}_{\mathrm{P} / \mathrm{DCW}}(\mathrm{g} /$ \\
\hline C. bombicola $^{\mathrm{a}}$ & Glucose, rapeseed oil & 168 & 1.70 & 0.47 & 0.077 \\
C. bombicola & Glucose, rapeseed oil & 378 & 2.15 & 0.58 & 0.096 \\
C. bombicola & Glucose, rapeseed oil & 221 & 1.55 & 0.48 & 0.068 \\
${\text { C. } \text { albicans }^{\mathrm{b}} \text {-13-1 }}^{\mathrm{b}}$ & Glucose, oleic acid & 300 & 1.59 & 0.60 & 0.023 \\
C. bombicola & Glucose, rapeseed oil & 1023 & 0.61 & 0.53 & 0.019 \\
C. bombicola $^{\mathrm{b}}$ & Glucose, waste food & 480 & 2.39 & 0.73 & 0.020 \\
\hline
\end{tabular}

a Fed-batch fermentation

b Semi-continuous fermentation

Figure captions

Fig. 1. Sophorolipids produced by C. bombicola. A. Acidic-form SLs; B. Lactone-form SLs. These structures can be non- $(\mathrm{R} 1, \mathrm{R} 2=-\mathrm{OH})$, mono- $(\mathrm{R} 1=-\mathrm{OH}, \mathrm{R} 2=-\mathrm{OCH} 3)$, or di-acetylated $(\mathrm{R} 1, \mathrm{R} 2=-\mathrm{OCH} 3)$. 
(Chen et al., 2020)

Fig. 2.Semi-continuous fermentation platform (a. Fermentation broth inlet; b. Supernatant outlet; c. SLs export).

Fig. 3.The morphology and sedimentation of SLs at different $\mathrm{O} / \mathrm{S}$ ratios.

Fig. 4. SLs precipitation. A. Relationship between the sedimentation height ratio of SLs and the concentration. B. Relationship between the average sedimentation rate of SLs and O/S.

Fig. 5.Parameters related to SLs precipitation. A. SLs particle size. B. Viscosity of fermentation supernatant. C. Density of SLs and oil mixture. D. Density of fermentation broth supernatant.

Fig. 6. Mechanism of SLs sedimentation.

Fig. 7. Ultrasonic assisted SLs deposition. A. $100 \mathrm{~W}$ ultrasonic power. B. $200 \mathrm{~W}$ ultrasonic power. C. 300 $\mathrm{W}$ ultrasonic power. D. Maximum sedimentation rate at different power.

Fig. 8.Ultrasound-assisted in-situseparation. A. SLs titer. B. Residual oil, glucose and DCW concentration. C. Productivity and yield of SLs.

Fig. 1

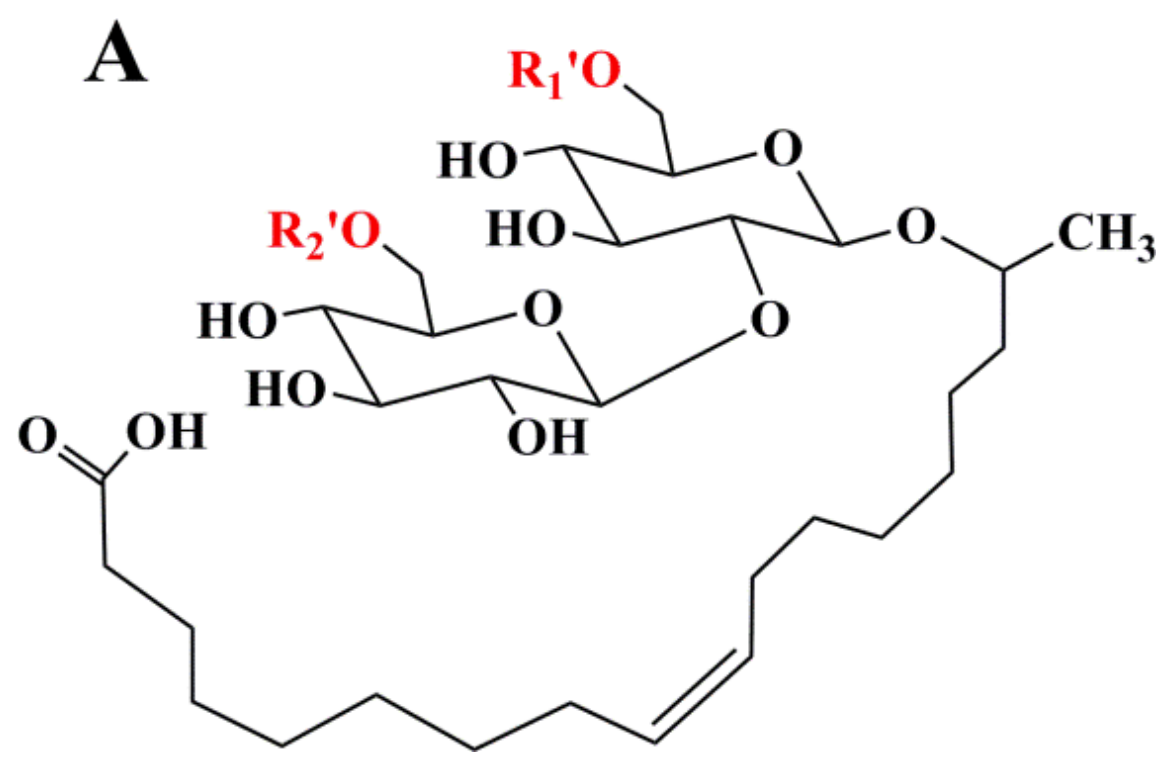




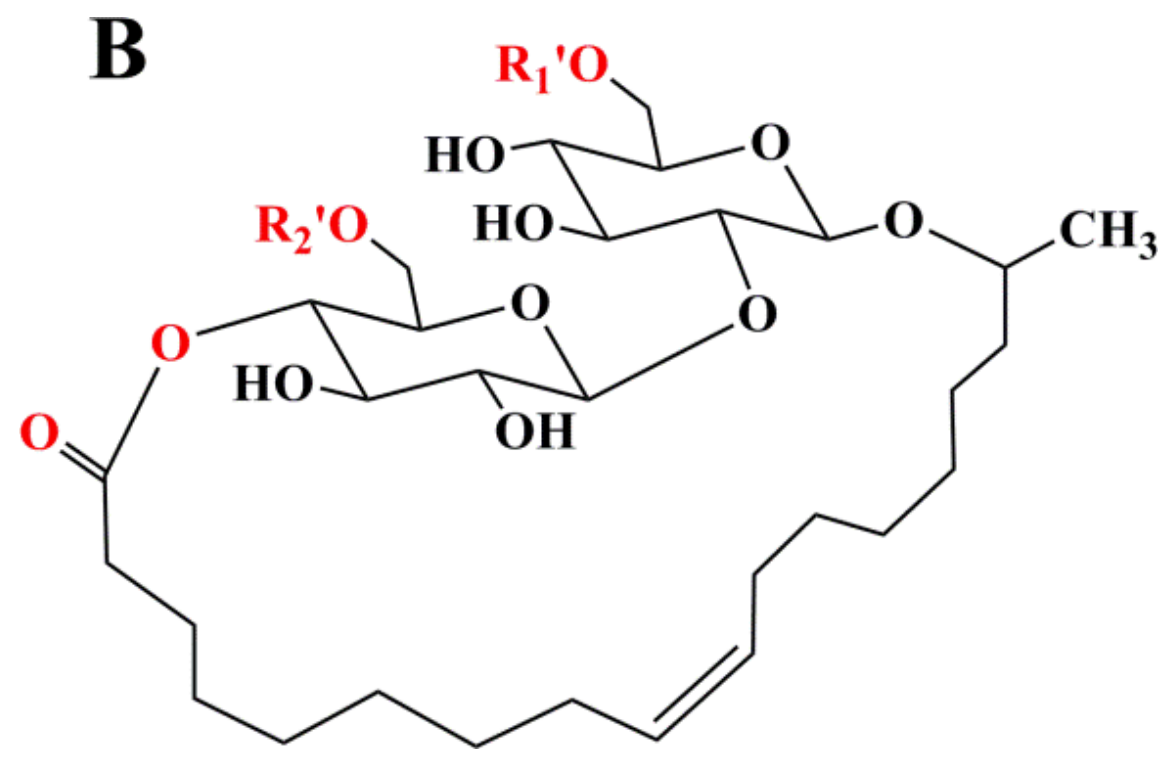

Fig. 2

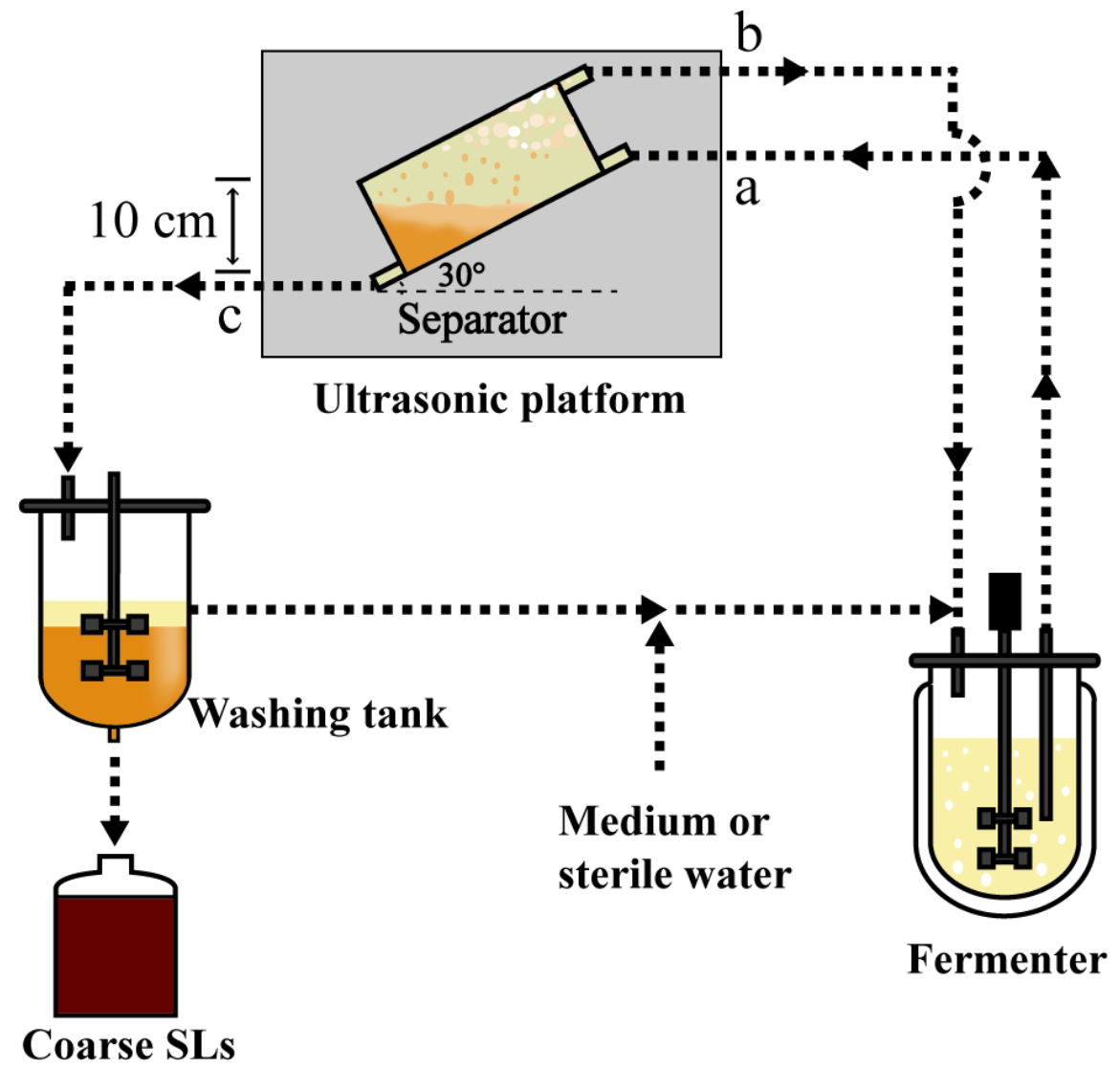

Fig. 3 


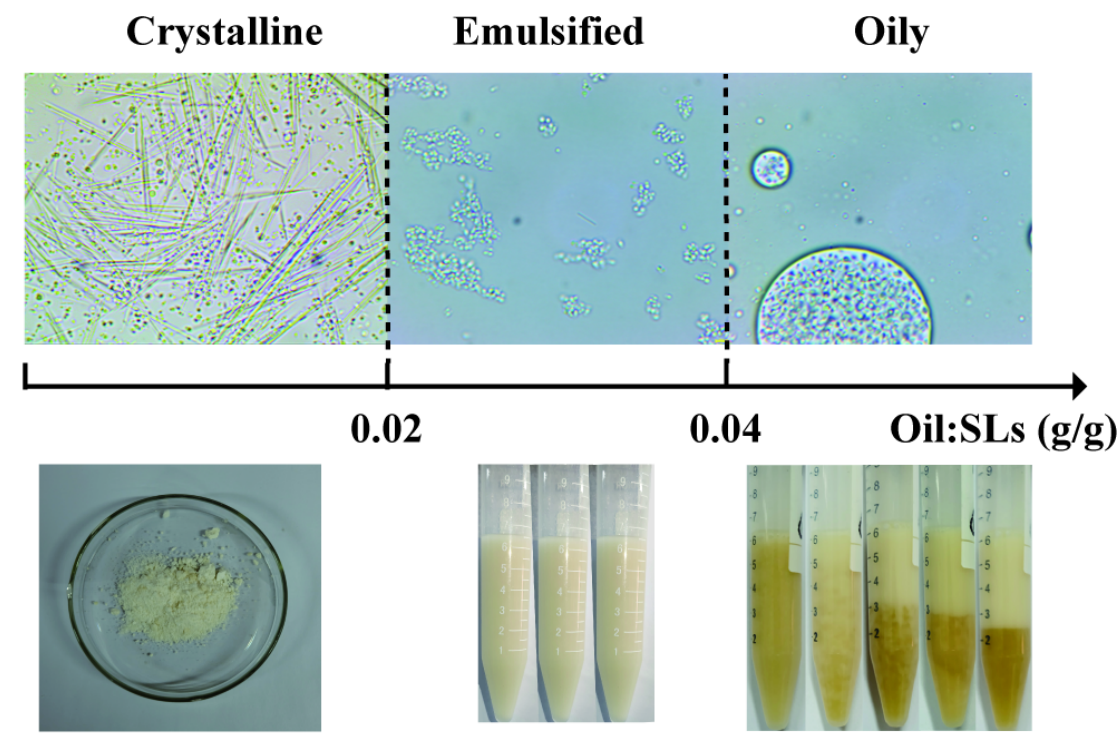

Cooling crystallization

Gravity precipitation

Fig. 4

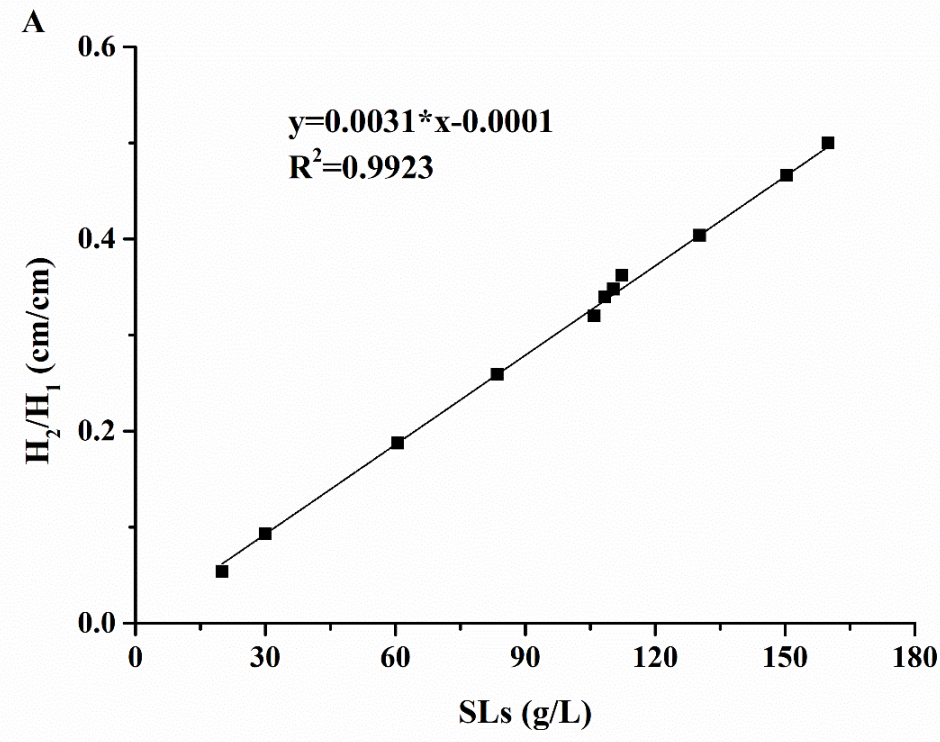




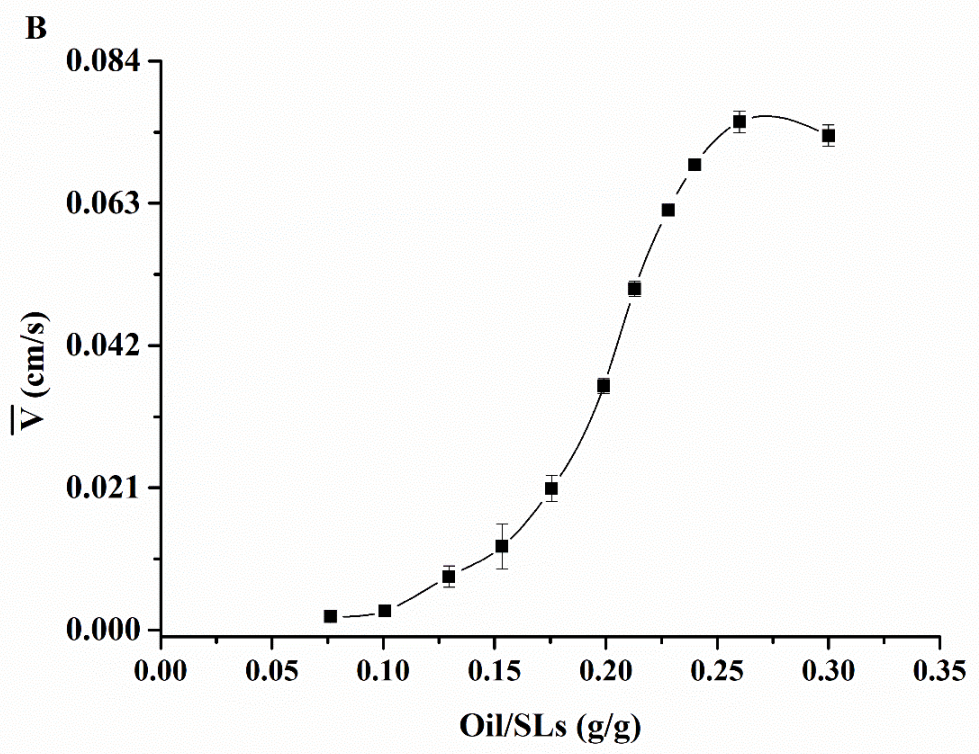

Fig. 5

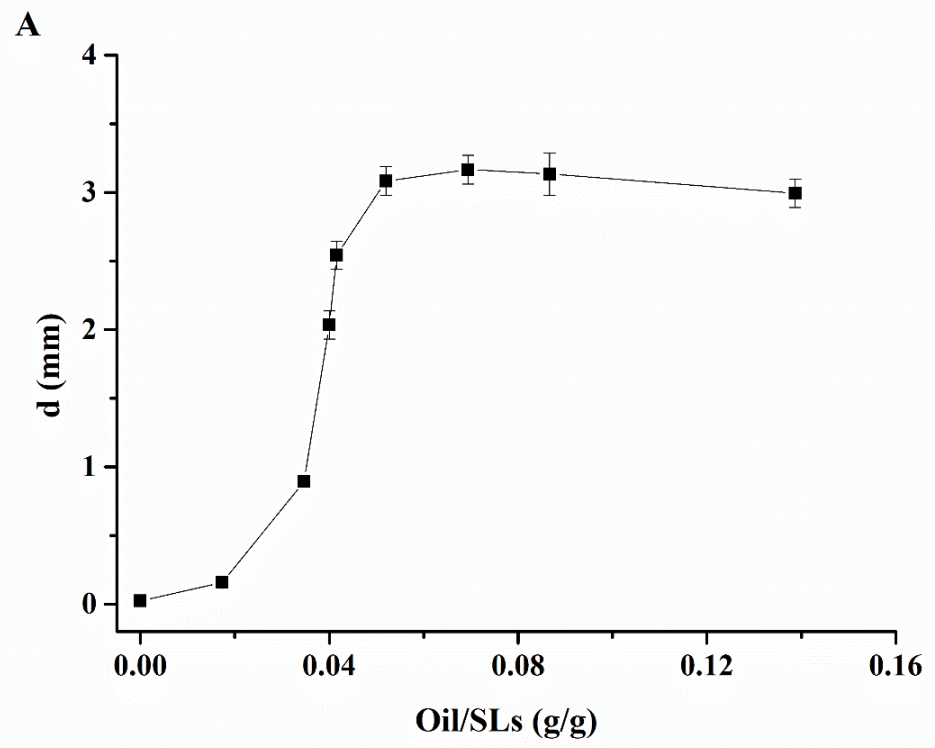



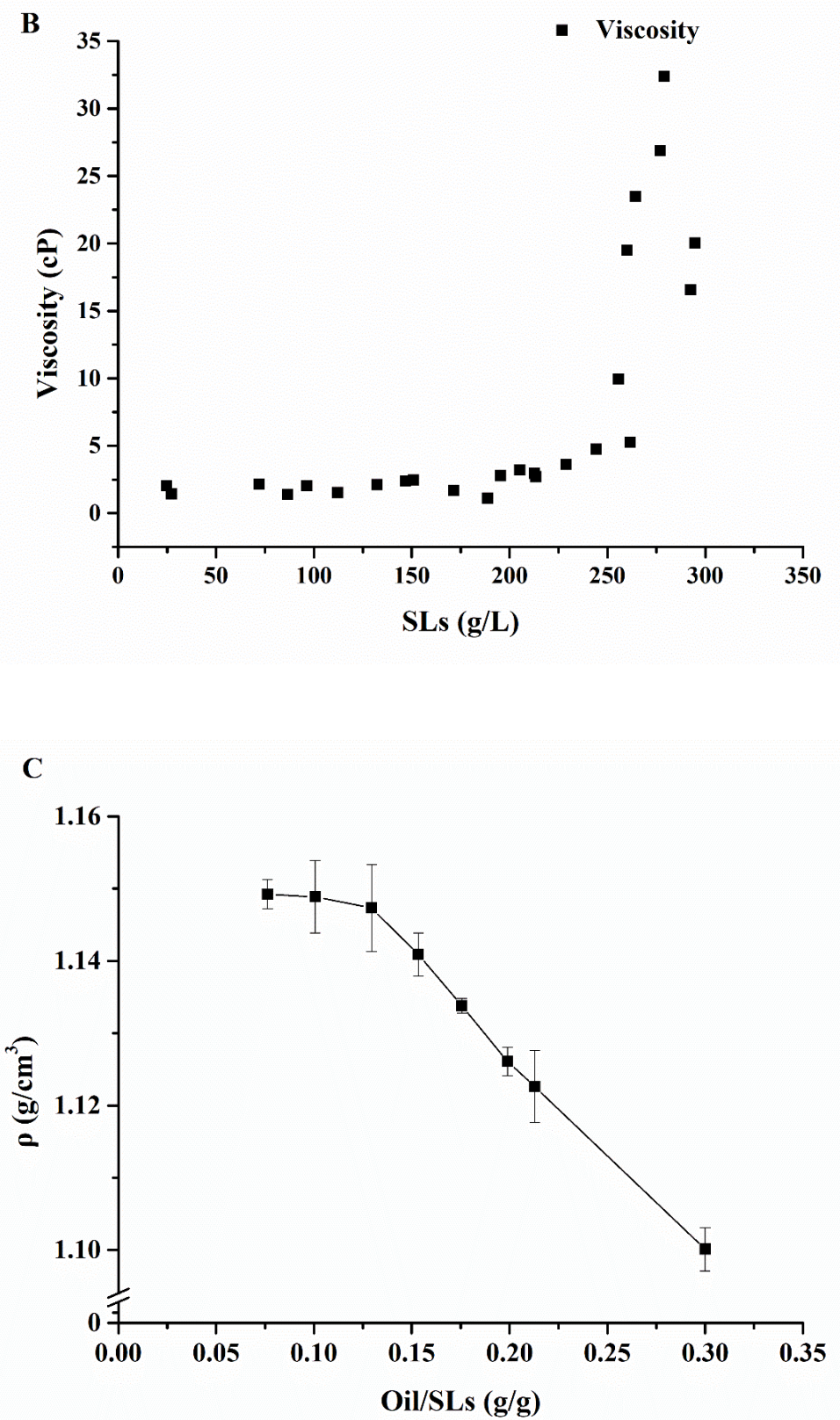


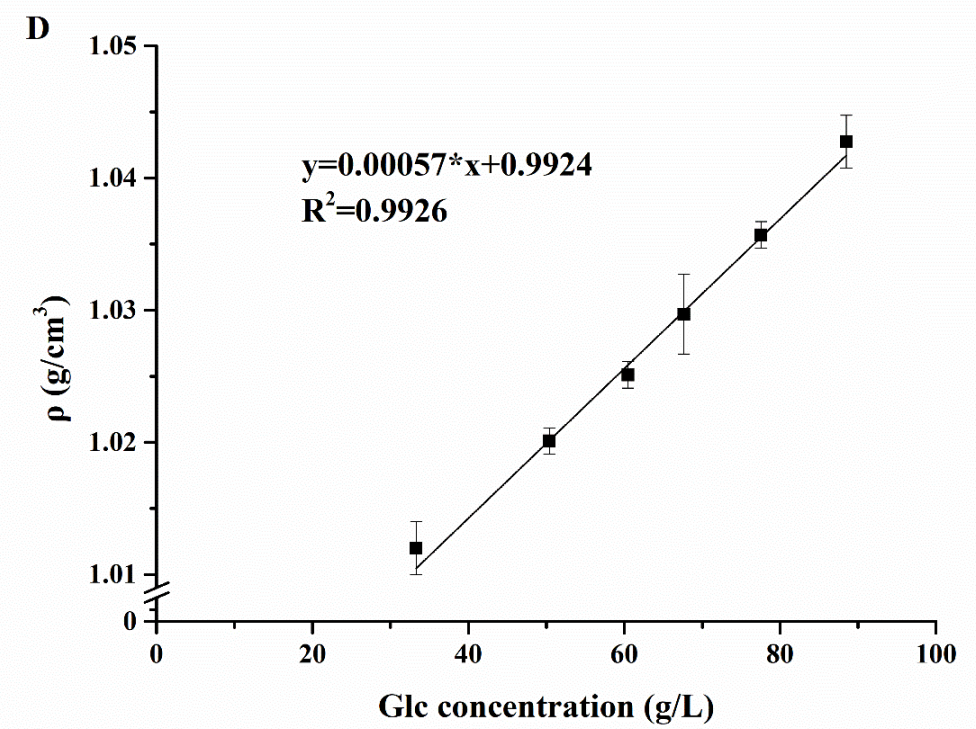

Fig. 6

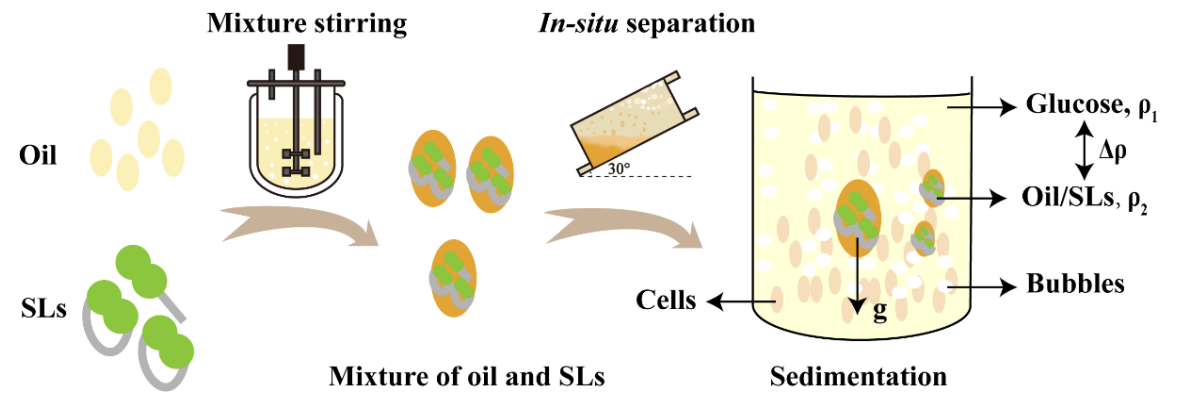

Fig. 7 

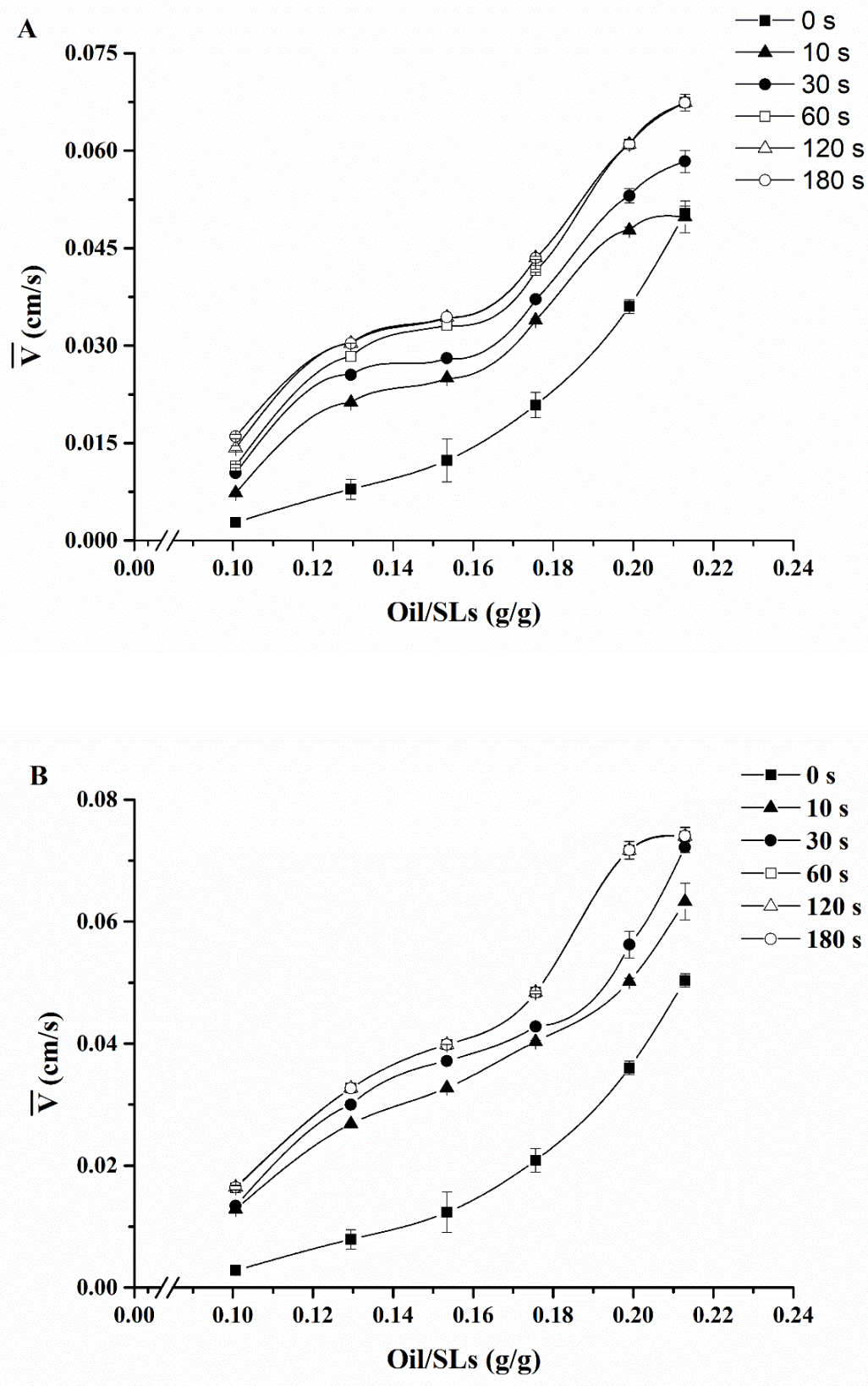

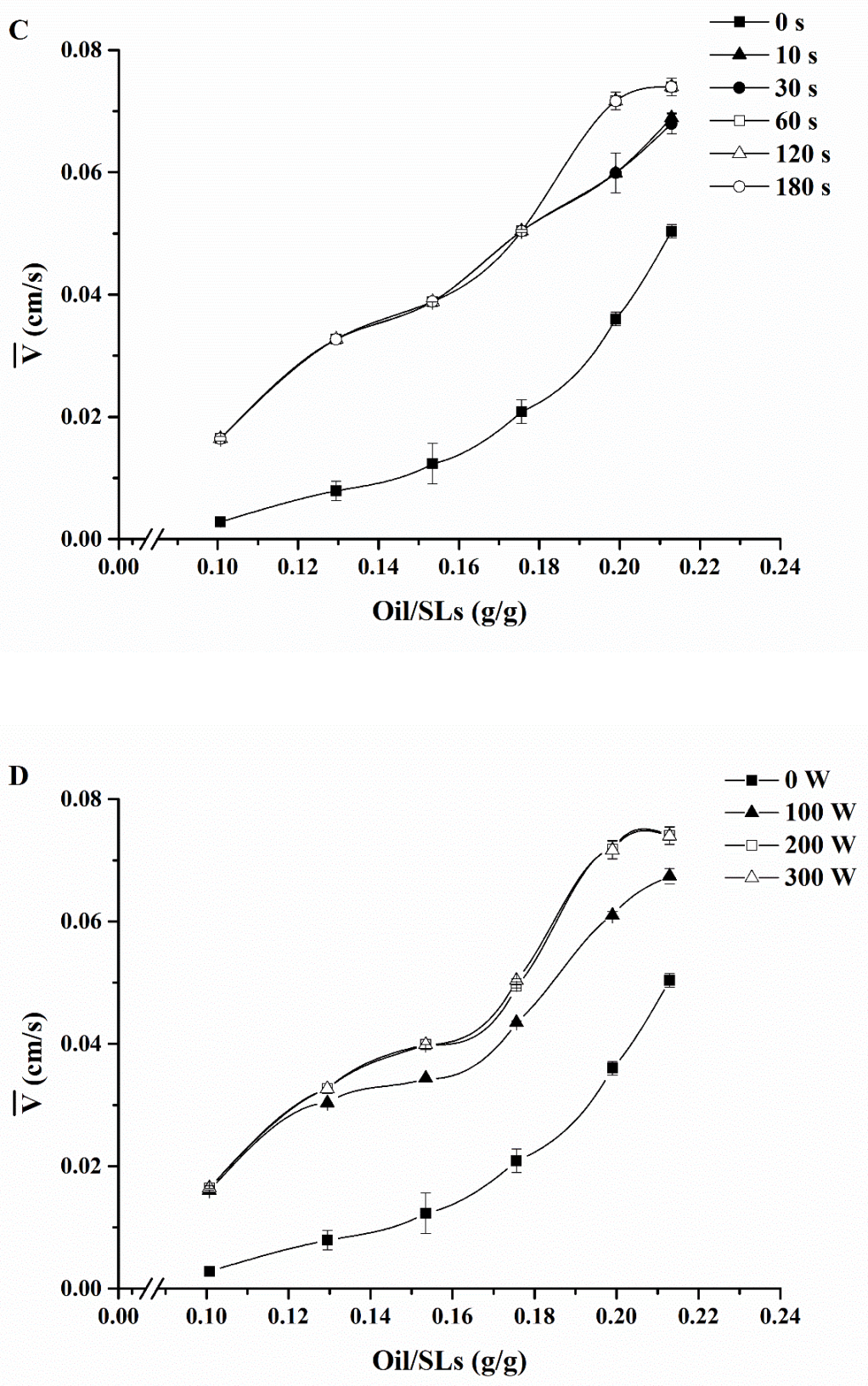

Fig. 8 

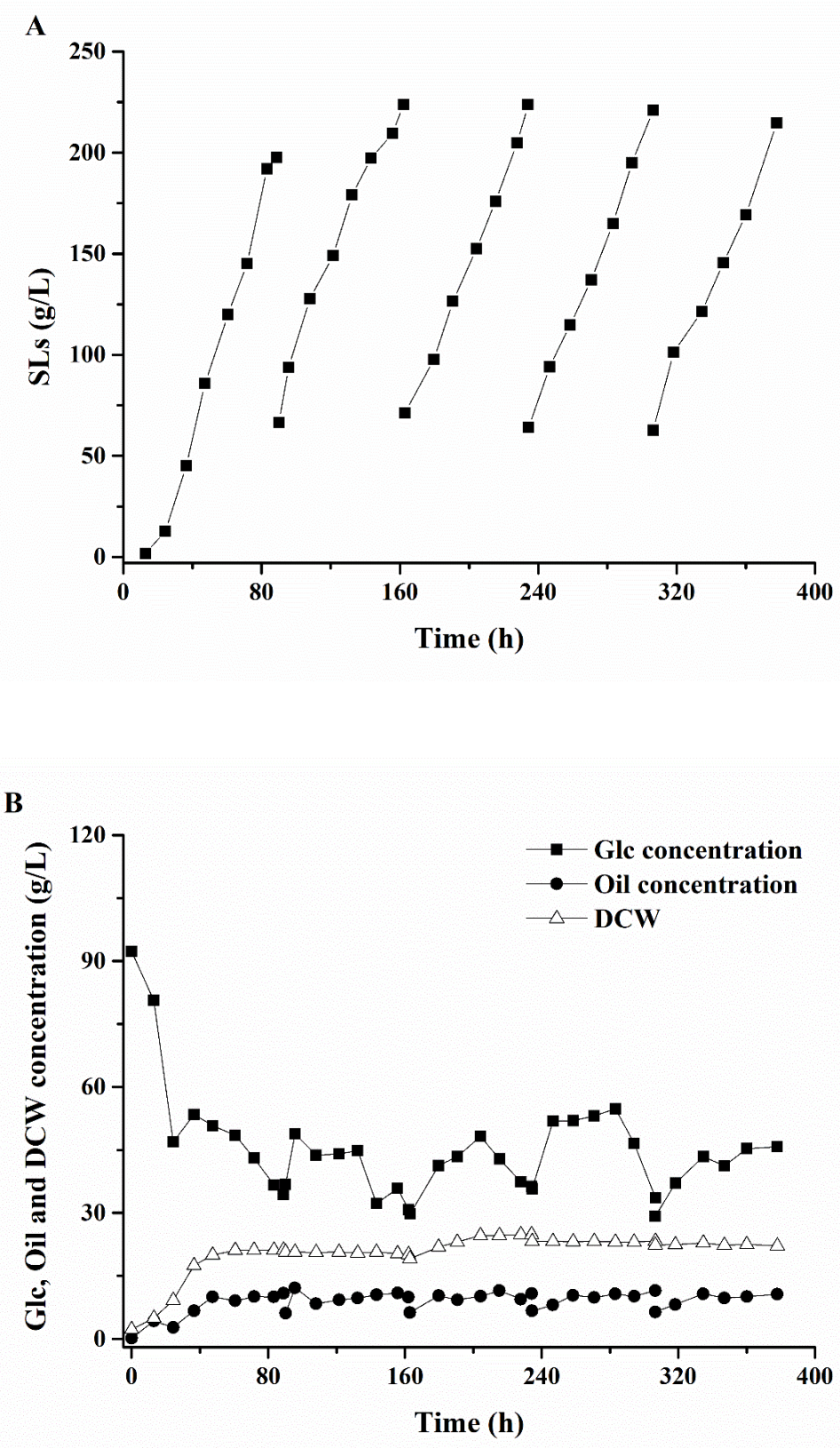


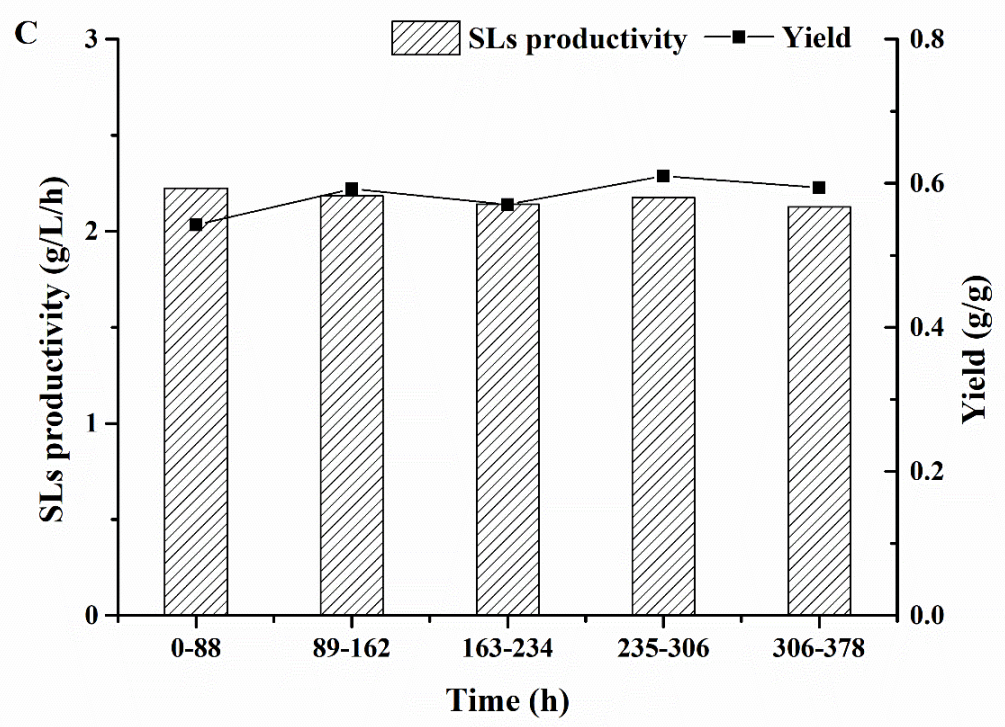

